\title{
Diálogos Com Uma Política Pública De Formação De Professores Que Ensinam Matemática Na Inglaterra: O Caso Do Maths Hubs
}

\author{
Dialogues With A Mathematics Teacher Training Public Policy In England: \\ The Case Of The Maths Hubs
}

\begin{abstract}
Resumo
Esse artigo tem como objetivo descrever e analisar uma política pública de formação continuada da Inglaterra denominada de Maths Hubs. A descrição realizada leva em conta os campos administrativos, operacionais e conceptuais. A análise é empreendida a partir da mobilização de diálogos com políticas públicas brasileiras, sem desconsiderar o contexto em que ações dessa natureza são realizadas. Os diálogos construídos auxiliaram na compreensão da política inglesa, bem como ampliam a compreensão sobre as ações brasileiras de formação continuada de professores de matemática, sem deixar de lado a devida crítica à importação ingênua de modelos que pasteuriza a educação mundial, diminuindo os espaços de criatividade.
\end{abstract}

Palavras-chave: Educação Matemática, Políticas Públicas, Formação de Professores, Maths Hubs

\begin{abstract}
This paper aims to describe and to analyse a public policy of teacher training in England called Maths Hubs. The description considers administrative, operational and conceptual fields. The analysis is undertaken through the mobilization of dialogues with Brazilian public policies, without disregarding the context in which actions of this nature are carried out. The dialogues helped to understand English policies, as well as increase the understanding of the Brazilian actions teaching training of mathematics teachers, without neglecting due criticism to the naive importation of models that pasteurize world education, reducing the spaces of creativity.
\end{abstract}

Keywords: Mathematics Education, Public Policy, Teacher Training, Maths Hubs

\footnotetext{
* Doutor em Educação Matemática - UNESP/Rio Claro. Professor do Programa de Pós-Graduação em Educação em Ciências e em Matemática, UFPR, Curitiba, Paraná, Brasil. E-mail: rolkouski@uol.com.br.
} 


\section{Introdução}

O trabalho de formação continuada de professores é desafio tanto em países desenvolvidos como em países em desenvolvimento. Tal trabalho ocorre em diferentes escalas. No Brasil, podemos vislumbrar situações de relevância indiscutível e que demandam um grande investimento financeiro e de recursos humanos com resultados qualitativos de excelência, mas capazes de atingir diretamente poucos profissionais, como os programas de doutorado em educação. A escala passa a ser ampliada, quando passamos pelos mestrados acadêmicos e profissionais, pelos mestrados profissionais em rede, pelos programas de pós-graduação lato senso e, em outro nível, poderíamos incluir iniciativas no âmbito das Universidades via projetos de pesquisa e/ou extensão.

Cada uma dessas iniciativas possui o seu valor e o movimento de pesquisa na área educacional tem se debruçado a avaliar seus impactos em um processo permanente de autocrítica. Neste artigo, porém, trata-se de outra faceta da formação continuada. As formações que são decorrentes de políticas públicas que visam a atingir uma grande escala de professores. Entendemos políticas públicas de acordo com Teixeira (2002, p. 2):

... são diretrizes, princípios norteadores de ação do poder público; regras e procedimentos para as relações entre poder público e sociedade, mediações entre atores da sociedade e do Estado. São, nesse caso, políticas explicitadas, sistematizadas ou formuladas em documentos (leis, programas, linhas de financiamentos) que orientam ações que normalmente envolvem aplicações de recursos públicos.

Ainda que, em nosso país, tenhamos percebido um processo de desarticulação de tais políticas nos últimos anos, é notável o acúmulo de expertise, decorrente, tanto da variedade de políticas $^{1}$ em nível federal como em nível estadual, como de sua singular e histórica continuidade. Para citarmos alguns exemplos em nível federal, o PIBID - Programa Institucional de Bolsas de Iniciação à Docência, iniciado em 2010, o Pro-letramento, iniciado em 2006 e substituído pelo PNAIC - Programa Nacional pela Alfabetização na Idade Certa, em 2012 e alguns programas estaduais, como o Folhas ${ }^{2}$, iniciado em 2003 e o PDE $^{3}$ - Programa de Desenvolvimento Educacional, iniciado em 2010, ambos no estado do Paraná.

Assim como no Brasil, outros países têm se dedicado a fomentar tais ações e vemos no diálogo com essas políticas as possibilidades de ampliar a compreensão sobre seus e nossos limites e possibilidades. Nesse sentido, nos dedicaremos a descrever uma política pública de

\footnotetext{
${ }^{1}$ A menção a essas políticas não significa que são as mais importantes.

${ }^{2}$ Em Parcianello (2015) pode-se encontrar maiores informações sobre o projeto.

${ }^{3}$ Em Nesi \& Zanella (2016) há uma análise crítica sobre os limites e possibilidades dessa política.
} 
formação continuada de professores de Matemática que se desenvolve desde o ano de 2012 na Inglaterra, denominada de Maths Hubs. Tal descrição será articulada com comentários do pesquisador frente à experiência brasileira, o que não deve sugerir, de início, um viés de importação se ações, razão pela qual, teceremos alguns comentários a esse respeito na seção seguinte.

\section{Sobre A Alienação, Aprendizado, Importação E Seus Perigos}

No ano de 2017, a Base Nacional Comum Curricular foi aprovada, após uma série de críticas $^{4}$, dentre elas a aproximação com o currículo Australiano ${ }^{5}$. De maneira semelhante, os Parâmetros Curriculares Nacionais também sofreram críticas pela aproximação com o currículo espanhol. Assim se posiciona Célia Maria Carolino Pires, em entrevista dada à pesquisadora Karen Gonçalves Britis:

[...], corria a história de que o currículo era idêntico ao currículo espanhol ou era quase uma cópia do currículo espanhol. Essa história circulou Brasil afora. Francamente, quando se elabora qualquer documento curricular é necessário consultar o que tem em outros países.

Por conta do doutorado, havia feito um mapeamento de documentos curriculares de vários países procurando olhar a ideia de rede que era o foco do meu doutorado. Pesquisei as Propostas Curriculares de Matemática da Itália, dos Estados Unidos, de Portugal, da Espanha, do Japão entre outras, percebendo e analisando as características dessas propostas. Nesse grupo do MEC, obviamente, até por um dever de oficio, nós aprofundamos esse debate sobre o que era proposto nos currículos de outros países. Chegamos à conclusão de que há muito mais similaridades em Matemática do que diferenças.

Quanto aos blocos de conteúdos, as grandes questões, os eixos metodológicos, é perceptivel um discurso mais ou menos padrão em todos os países. Nos últimos anos, no período em que elaboramos os PCN, não existia qualquer currículo mundial que não desse grande ênfase à resolução de problemas como um eixo metodológico e à questão das tecnologias.(Britis, 2017, p. 82)

Concordando com a professora Célia, ao elaborar propostas curriculares ou outras ações, como políticas públicas de formação de professores, o olhar para o outro é salutar, o que não implica em sua importação. A importação pura e simples é tão ingênua quanto a alienação e por vezes traz um prejuízo ainda maior.

Vejamos o exemplo da reforma do Ensino Médio. Uma das justificativas para a implantação de tal reforma era alinhar o itinerário com outros países. Argumentou-se que o Brasil possuía itinerário único e vários países, incluindo a Inglaterra, possibilitavam escolhas

\footnotetext{
${ }^{4}$ Ao leitor interessado, recomendamos os artigos publicados na edição temática da Revista Horizontes: REVISTA HORIZONTES. (2018). BNCC: Um novo capítulo da educação em migalhas? v. 36 (1).

${ }^{5}$ Uma comprovação desse vínculo é dada pelo fato que o documento foi avaliado pela ACARA - Australian Curriculum, Assesment and Reporting Authority (http://movimentopelabase.org.br)
} 
aos alunos de Ensino Médio oferecendo itinerários flexíveis. A reforma foi então proposta e aceita e os sistemas de ensino deverão ofertar um dos itinerários possíveis.

No entanto, o que não se observou é que, ao contrário dos outros países, a maior parte dos municípios brasileiros possui uma única escola pública de Ensino Médio. É fácil perceber que, ao estudante que não possui condições econômicas de se deslocar para outra cidade será obrigado a frequentar o percurso que lhe é oferecido pela sua cidade. Muito provavelmente será a Educação Profissional o que poderá limitar o seu acesso ao Ensino Superior e aos conhecimentos de base de outras disciplinas que não a Matemática e a Língua Portuguesa, o que aumentará ainda mais o fosso entre os alunos de classes mais favorecidas e o de classes menos favorecidas ${ }^{6}$.

Isso não significa que não podemos aprender com os outros países, mas deve significar que não devemos importar os seus modelos, independente do sucesso alcançado. Dessa maneira, o que faremos aqui é convidar o leitor a um exercício de leitura conjunta, tomando como base algumas políticas públicas brasileiras. Tal exercício de leitura, não pode prescindir de um conhecimento contextual em que as políticas públicas são criadas e efetivadas. Nesse sentido, concorda-se com Imbernón (2009, p. 9-10), segundo o qual:

Hoje em dia, não podemos falar nem propor alternativas para a formação permanente (do professor) sem antes analisar o contexto político e social (de cada país, cada território) como elemento imprescindível na formação, já que o desenvolvimento das pessoas sempre tem lugar num contexto social e histórico determinado...

Cabe a próxima seção trazer então, alguns elementos contextuais que possam auxiliar o leitor a criar uma imagem mental do contexto em que a política pública Maths Hubs foi criada e tem sido desenvolvida.

\section{Algumas Considerações Contextuais}

O Maths Hubs se desenvolve na Inglaterra, país com 51 cidades e uma população de pouco mais de 53 milhões de habitantes, em uma área de 130 278,43 quilômetros quadrados, o que resulta em uma alta densidade demográfica (406 hab. $/ \mathrm{km}^{2}$ ) em comparação com as características brasileiras, cuja população é de mais de 200 milhões de habitantes, em uma área de $8515767,049 \mathrm{~km}^{2}$ e uma densidade de 23,8 habitantes por quilômetro quadrado.

Ressalta-se que, embora com uma expressiva população, a Inglaterra possui uma alta

\footnotetext{
${ }^{6}$ Uma problematização referente à implantação do Novo Ensino Médio pode ser consultada em Gonçalves (2017) e Ferreti \& Silva (2017).
} 
concentração em um pequeno número de cidades, o que facilita a administração e a disseminação de políticas públicas, o que não ocorre no Brasil que possui 5570 municípios, muitos deles apenas com acesso via fluvial ou marítima, por estradas precárias ou via aérea.

Com relação ao sistema educativo, a Inglaterra tem o ensino dividido em Primary (5 a 11 anos de idade) e Secondary Schools (11 a 16 anos de idade). Tais níveis são divididos em blocos de dois a quatro anos cada, denominados de Key Stages, antes disso há os Early Years (3 a 5 anos de idade). É também relevante para esse estudo, observar que há, em três situações da escolaridade, avaliações, sendo a mais importante para a vida escolar do aluno o GCSE General Certificate of Secondary Education, pois, a partir da nota obtida nesse exame, o aluno será ou não aceito na Universidade e dessa nota também dependerá estar ou não apto a seguir a carreira de professor primário ${ }^{7}$.

A formação inicial do professor de Matemática na Inglaterra é bastante difusa, havendo vários itinerários possíveis, sendo que, o equivalente ao brasileiro - Ensino Médio e Licenciatura em Matemática - é o menos comum. Para iniciar a formação, é necessário ter obtido notas mínimas em Inglês, Matemática e Ciências no GCSE e passar em um teste que avalia habilidades básicas de alfabetização. No entanto tal formação não é obrigatória, ainda que haja vantagens para os professores que a tenham feito.

Após a Secondary School, os alunos podem seguir em sua formação nos denominados $A$ 's levels (16 a 18 anos). Trata-se de estudos avançados que auxiliam ao aluno no ingresso à Universidade. Para lecionar nos A's levels, os professores frequentam os PGCE-Postgraduate Certificate in Education. Além da possibilidade de lecionar nos A's levels, o PGCE abre as portas ao professor para se tornar líder de área nas escolas em que atua. Trata-se de um curso de um ou dois anos, em que, ao final é necessário apresentar uma monografia.

É importante ressaltar que, na Inglaterra, em quaisquer dos cursos de formação de professores, grande parte da carga horária é realizada na escola e em serviço. A Universidade vai a escola, no sentido de desenvolver observações, práticas e reuniões de trabalho. Como observaremos, tal desenho impacta também no desenvolvimento das políticas públicas. Os professores participantes do Maths Hubs, são, em geral, profissionais sem o que, no Brasil, se entende de formação específica em Matemática.

\footnotetext{
${ }^{7}$ www.gov.uk/national-curriculum.
} 


\section{O Maths Hubs}

Cada Maths $H u b s^{8}$ é uma parceria, liderada localmente por uma escola ou colégio com o objetivo de auxiliar no desenvolvimento profissional de professores de matemática baseado no conceito de Teaching for Mastery, sobre o qual falaremos adiante.

\subsection{Promoção E Financiamento}

O Maths Hubs é coordenado pelo National Centre for Excellence in the Teaching School (NCETM), e financiado pelo Departamento de Educação da Inglaterra que fornece subsídios financeiros para cobrir despesas operacionais. O projeto também abre a possibilidade de estabelecer outras parcerias com Universidades e instituições ligadas à Educação.

Comentários: Da mesma maneira que a política pública inglesa, os programas de formação continuada em larga escala brasileiros recebem financiamento do Governo Federal. Por outro lado, ao contrário do que comumente ocorre no Brasil, a coordenação pedagógica do Maths Hubs fica a cargo de uma sociedade civil, sem fins lucrativos, representativa da Educação Matemática inglesa, o NCETM.

No Brasil, a SBEM - Sociedade Brasileira de Educação Matemática, não têm espaço institucional na coordenação geral de políticas públicas similares, como o GESTAR I e II Gestão da Aprendizagem Escolar (Brasil, 2007; 2013), o Pró-Letramento (Brasil, 2012a) e mais recentemente o PNAIC - Pacto Nacional pela Alfabetização na Idade Certa (Brasil, 2014), embora se possa observar a inserção de pesquisadores ligados à SBEM em coordenações locais e como autores dos materiais de formação. Por outro lado, é digno de nota que há sim políticas públicas, como o PROFMAT ${ }^{9}$ - Mestrado Profissional em Rede e OBMEP ${ }^{10}$ - Olimpíada Brasileira de Matemáticas de Escolas Públicas, que são coordenadas pela SBM - Sociedade Brasileira de Matemática. Tais políticas, no entanto, possuem concepções distintas das citadas.

A coordenação, quando realizada por sociedades, assim como ocorre nos Maths Hubs possibilitam o desenvolvimento de vários projetos paralelos junto a diferentes Universidades. Além disso, tal coordenação poderia trazer uma maior estabilidade a tais políticas que são historicamente marcadas pela descontinuidade.

8 Essa e outras informações foram obtidas do site do programa www.mathshubs.org.uk. O site não se encontra disponível para acesso no Brasil. Para acessá-lo no solo brasileiro o leitor interessado deverá instalar um serviço de VPN para acessar conteúdos bloqueados.

${ }^{9}$ Para saber mais sobre o PROFMAT pode-se acessar http://www.profmat-sbm.org.br.

${ }^{10}$ Para saber mais sobre a OBMEP pode-se acessar http://www.obmep.org.br/. 


\subsection{Operacionalização E Alcance}

Embora possa se visualizar vários projetos paralelos, o principal eixo de atuação é o Teaching for Mastery Programme. Nele, dois professores de cada escola, chamados de líderes, participam de um Grupo de Trabalho, também chamado de Grupo de Professores Pesquisadores que se reúne regularmente. Tal grupo é constituído por seis ou sete escolas e coordenado por um Mastery Specialist. Os líderes, por sua vez, reúnem-se regularmente com os professores de seu Maths Hubs. O programa tem a periodicidade de dois anos, sendo que no primeiro ano o trabalho é orientado pelo Mastery Specialist e no outro ano se desenvolve de forma mais independente.

Podemos visualizar o funcionamento dos Maths Hubs no organograma a a seguir:

\section{Mastery Specialist}

\section{Líderes de Escola •14 líderes, 2 de cada escola}

\section{Professores}

- Cada líder trabalha com os professores de seu Maths Hub

Figura 1: Organograma do Maths Hubs Fonte: elaborado pelo autor.

O Mastery Specialist recebe formação específica e é vinculado ao NCETM. Cada um dos líderes de escola é selecionado por um processo que envolve o NCETM, o Departamento de Educação e o National College for Teaching and Leadership. Já os professores, participam do programa de forma voluntária.

O Maths Hubs iniciou suas atividades em 2014 e conta atualmente com 35 Maths Hubs que envolvem duas mil escolas e tem a intenção de envolver dez mil, ou seja, metade das escolas da Inglaterra até o fim de 2023. O Maths Hubs está presente em todas as cidades inglesas e inclui todos os níveis de ensino.

Comentários: Observa-se que o modelo adotado pelas políticas de formação de professores brasileiras em larga escala é semelhante ao adotado pelo programa inglês, qual seja, o modelo de rede. Por outro lado, há uma diferença fundamental que auxilia na coordenação pedagógica e diminuiria os problemas advindos da esfera político partidária, sobretudo em 
municípios menores ${ }^{11}$. O vínculo que o Maths Hubs estabelece é com a escola, já nos programas federais brasileiros o vínculo é com as secretarias municipais de educação. Se por um lado, o vínculo com as secretarias tem como vantagem o engajamento do ente público, por outro lado, o uso da estrutura pedagógica para fins político partidários traz uma desvantagem que pode, muitas vezes, trazer prejuízos pedagógicos incontornáveis. Além disso, conforme constado nos últimos anos, as políticas públicas de formação brasileiras, ao serem coordenadas pelo Ministério da Educação, se fragilizam quando a política brasileira se fragiliza.

\subsection{Sobre A Concepção De Educação Matemática Do Maths Hubs}

O Maths Hubs se caracteriza por um programa de implementação curricular. A alteração do currículo inglês ocorreu em 2014 e foi influenciado pelo currículo de Cingapura, Xangai e Hong Kong pelo grande sucesso obtido pelo Sul Asiático no exame PISA - Programme for International Student Assessment.

Há um maciço e constante investimento para que o Mastery Approach seja adotado por todas as escolas da Inglaterra. Tal influência é abertamente anunciada em sites oficiais.

O Mastery Approach do sul da Ásia para o ensino de matemática está prestes a se tornar um padrão nas escolas primárias da Inglaterra, graças a uma grande expansão anunciada hoje pelo ministro das Escolas, Nick Gibb.

Com a ajuda de até 41 milhões de libras de financiamento, mais de 8.000 escolas primárias - metade do número total na Inglaterra - receberão apoio para adotar a abordagem, que é usada por alguns dos principais especialistas em matemática do mundo, incluindo Xangai, Cingapura e Hong Kong. (Department for Education, 2016)

O Mastery Approach está baseado em cinco grandes ideias que podem ser visualizadas no diagrama a seguir:

\footnotetext{
${ }^{11}$ Como exemplo desses problemas, podemos citar a pesquisa de Santos (2017), que se refere à "tumultuosa" implantação do PNAIC em Dois Vizinhos, município paranaense de cerca de 40 mil habitantes, devido à transição política.
} 


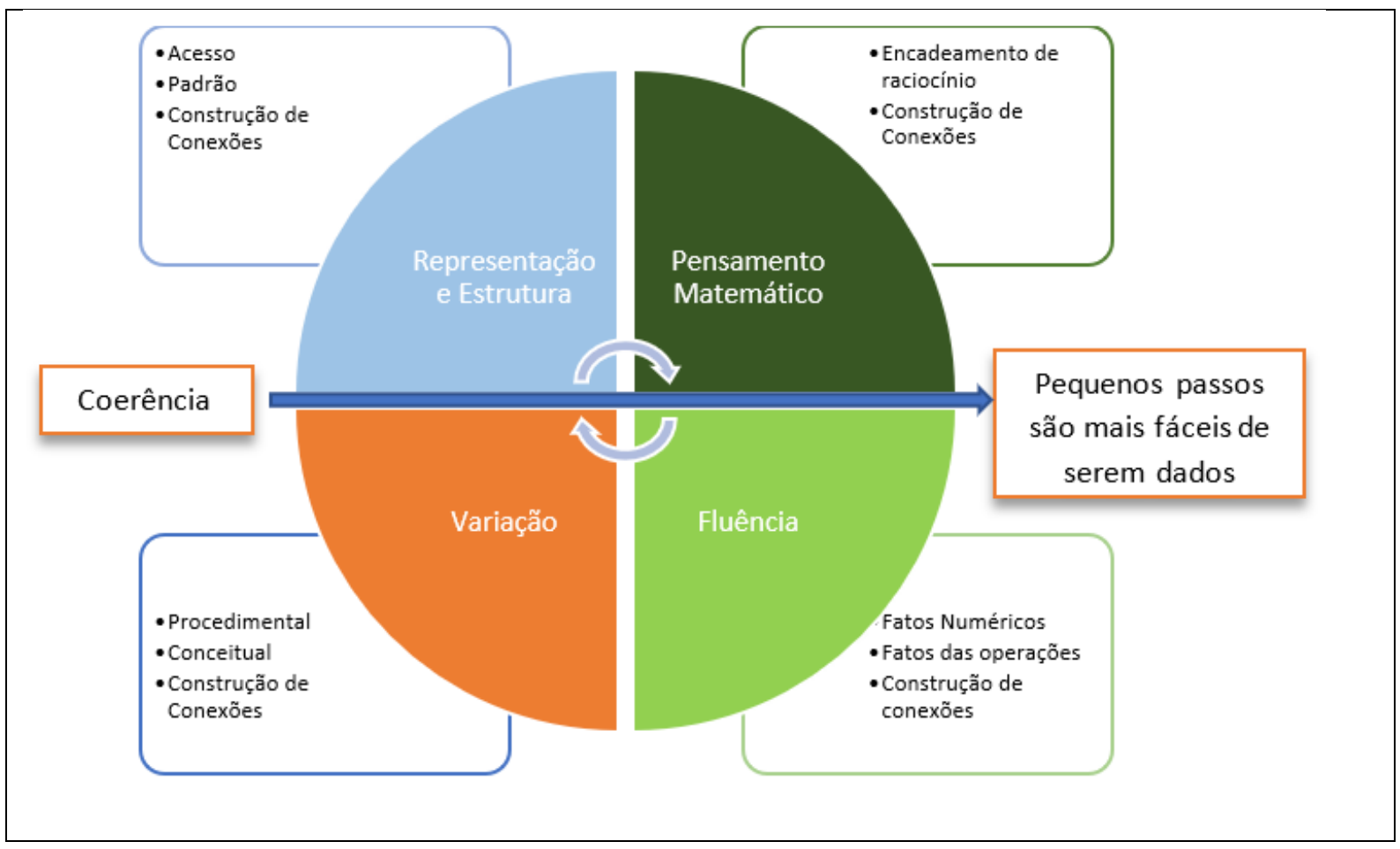

Figura 2: As cinco grandes ideias

Fonte: NCETM, 2017 (tradução do autor)

As cinco grandes ideias são assim enunciadas:

Coerência: Novas ideias devem estar conectadas a conceitos já compreendidos e dominados. Os passos dados devem ser pequenos para garantir o domínio e conexões.

Representação e Estrutura: as representações utilizadas devem expor a estrutura matemática, com a finalidade de que os alunos possam aos poucos resolver problemas sem apoio das representações.

Pensamento Matemático: se as ideias a serem ensinadas devem ser compreendidas profundamente, os alunos não podem receber informações passivamente e, sim, participar ativamente: pensando, raciocinando e discutindo com outros.

Fluência: rapidez e eficiência na recordação de fatos e procedimentos e a flexibilidade para se movimentar entre diferentes contextos e representações matemáticas.

Variação: variação dos modos que os conceitos são inicialmente apresentados aos estudantes, dando exemplos e não exemplos. Além disso, ao cuidadosamente variar as questões, evita-se a repetição mecânica e o pensamento matemático é encorajado.

Comentários: Conforme já salientado, o Maths Hubs tem como inspiração a Educação Matemática de origem chinesa. Podemos encontrar pontos de similaridade com a Educação Matemática brasileira no que se refere ao desenvolvimento do pensamento matemático, nos usos de perguntas como "Por quê?" "E se...?" e no uso de diferentes representações. Tais 
similaridades encontram eco em tendências como as Investigações Matemáticas em Sala de Aula (Ponte, Brocardo \& Oliveira, 2014) no caso do desenvolvimento do pensamento matemático e na Didática Francesa, notadamente nos trabalhos de Raymond Duval (Colombo, Flores \& Moretti, 2008).

Tendo em vista que os materiais de formação ingleses não possuem referência bibliográfica, não é possível compreender a origem exata das ideias que embasam o programa. Em outra direção, ao percorrer os materiais de formação brasileiros percebe-se o cuidado em explicitar as referências teóricas que os sustentam. Tais referências são úteis aos professores que desejam se aprofundar nos temas trazidos, além de permitir a diferentes tipos de leitores uma compreensão sobre as concepções presentes nos materiais.

\subsection{Mobilizando A Concepção}

A essa seção cabe apresentar como a concepção de Educação Matemática do Teaching for Mastery é mobilizada nos materiais de formação, em sala de aula e nas formações presenciais.

\subsubsection{Nos Materiais De Formação}

Para dar suporte à formação dos professores, o NCTEM elaborou diversos materiais que disponibiliza no site do programa. Trata-se de materiais escritos e em vídeo (lições e estudos de caso em sala de aula). Há ao todo 6 livros para os anos 1 a 6 (Primary School), um livro para o Secondary School e um livro denominado de Guia de Cálculo.

Com exceção do Guia de Cálculo, todos os livros possuem a mesma estrutura. Inicialmente apresentam os autores, fazem comentários sobre o Currículo Nacional e em particular sobre a abordagem (Mastery Approach). A partir daí, em cada um dos eixos são apresentados os tópicos curriculares, as grandes ideias relacionadas e como checar se os alunos estão ampliando seu domínio (Mastery Check), para, então, apresentar exemplos de encaminhamentos para desenvolver o domínio (Mastery) e o domínio com maior profundidade (Mastery with Greater Depth). Abaixo o exemplo da primeira página relacionada ao tema Adição e Subtração para o ano 4 (8 para 9 anos):

Quadro 1: Exemplos de encaminhamento sobre o tema Adição e Subtração

Tópicos Curriculares:

\section{Adição e Subtração}


Os alunos devem ser ensinados a:

- Subtrair e adicionar mentalmente números de quatro dígitos usando o método formal ou colunar ${ }^{12}$.

- Resolver problemas envolvendo adição e subtração de dois passos, decidindo o método e operação a ser usado e justificando-o.

\section{As Grandes Ideias:}

Antes de realizar a operação a criança deve saber estimar o resultado, por exemplo, 4786 - 2135 está próximo de 5000 - 2000, então a resposta deve ser próxima de 3000. Além disso, a criança deve ser capaz de utilizar métodos apropriados dependendo dos números que são somados ou subtraídos.

\section{Mastery Check:}

Por favor, note que as colunas seguintes fornecem exemplos de atividades e questões variadas que fornecem evidências sobre mastery e mastery with greater depth relacionados aos tópicos curriculares relacionados. Os alunos devem ser capazes de executar os procedimentos e responder às perguntas como as descritas, no entanto, o professor necessitará verificar se os alunos realmente compreendem as ideias perguntando "Por quê?", "O que acontece se..." e verificar se os alunos conseguem usar os procedimentos ou ferramentas para resolver problemas variados.

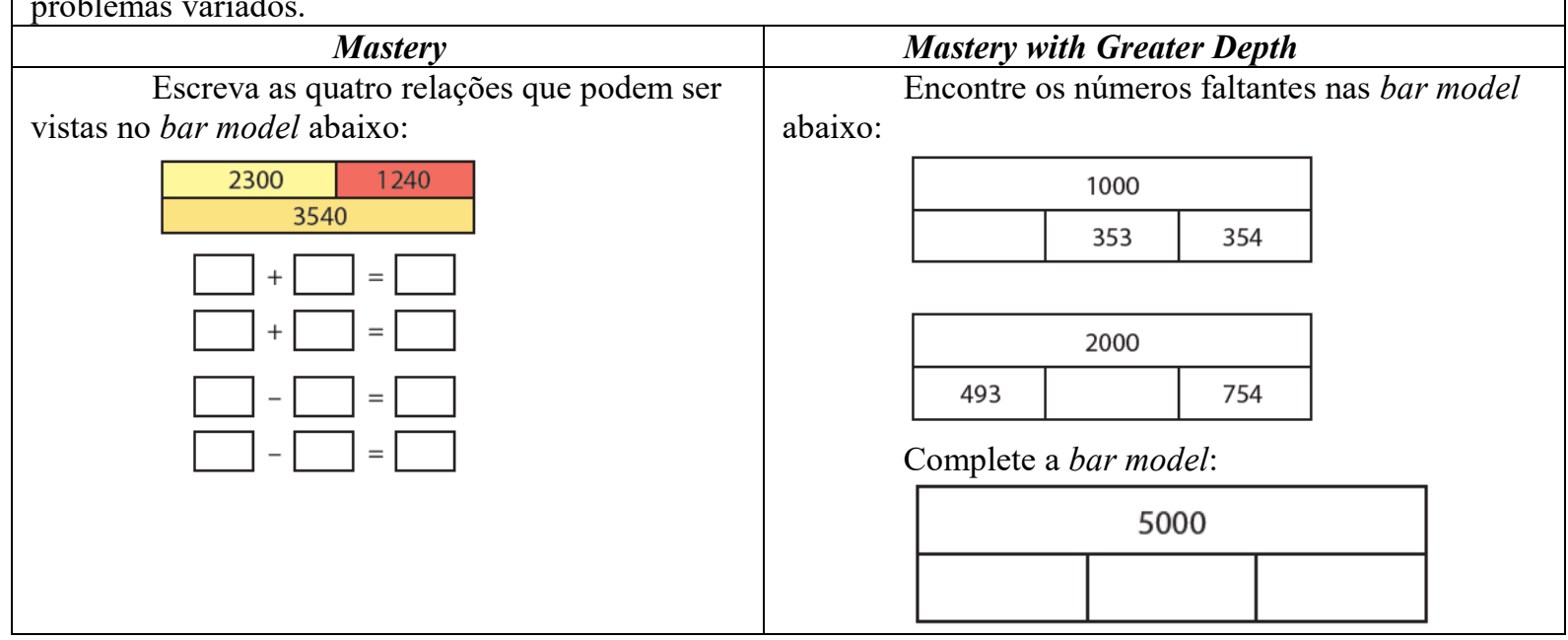

Fonte: ASKEW et al., 2015, Year 4, p. 12 (tradução do autor)

Observa-se no exemplo o uso das bar model $^{13}$, trata-se de uma representação empregada em grande parte dos materiais de formação. Além dessa representação há uma variedade de outras que são empregadas na resolução de problemas ou para desenvolver a fluência de cálculo.

Comentários: Ao estudar os materiais de formação, observa-se claramente as variações procedimentais, conceituais, o uso de diferentes representações e a progressão de atividades simples a complexas. Poucas das atividades contempladas nesses materiais poderiam ser realizadas de maneira mecânica. No entanto, como veremos adiante no uso do que é denominado Stem sentences, há, no programa como um todo, a presença de situações que podemos qualificar de repetitivas.

\footnotetext{
${ }^{12} \mathrm{O}$ método colunar é similar ao que denominamos de método por decomposição, sem, necessariamente apresentar

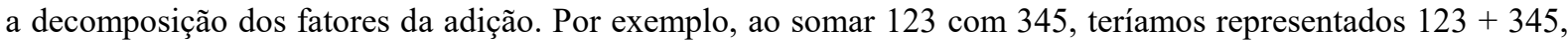
um fator sobre o outro e, a seguir, os números 8, 80, 400, para então, representar o resultado 488 .

${ }^{13}$ No Brasil, a professora Doutora Yuriko Yamamoto Baldin tem orientado trabalhos que se utilizam dessa representação, traduzido em seus estudos como "modelos de barra", dentre eles citamos: Cintra (2017), Góis (2014) e Queiroz (2014), dissertações de mestrado defendidas na Universidade Federal de São Carlos.
} 
Por outro lado, chama a atenção a completa ausência de elementos culturais na proposta inglesa que são caros à Educação brasileira, de forma geral, e particularmente à Educação Matemática. Sem dúvida que o processo imigratório no Brasil é bastante distinto da Inglaterra, no entanto, compreendemos que qualquer movimento de formação de professores de matemática não deveria desconsiderar a diversidade cultural presente em seu país.

\subsubsection{Nas Formações E Na Sala De Aula}

No dia 03 de maio de 2018, participei de uma formação dada aos líderes das escolas por uma Mastery Specialist a qual passo a relatar a seguir:

“A formação teve duração de 7 horas, com um intervalo de 30 minutos para o almoço. Após ter solicitado que todos refletissem sobre o andamento dos trabalhos nas escolas, a formadora solicitou que assistíssemos a uma aula do ano 3 sobre a introdução ao conceito de fração.

Todos se dirigiram à sala de aula. A aula iniciou a partir de slides projetados em uma televisão Touch Screen. A todo o momento o professor mostrava figuras pintadas pela metade e solicitava a um dos alunos que repetisse: “- O inteiro está dividido em duas partes iguais. Cada parte é uma metade”. Depois disso, solicitava que todos repetissem.

A partir daí o professor introduziu a notação de fração, nominando todos os termos: numerador, denominador e vínculo (traço de fração). Após esse primeiro momento, o professor solicitou que todos os alunos se agrupassem e distribuiu bandeirinhas de países entre eles para que dividissem em duas metades. Tendo em vista que algumas não apresentavam eixo de simetria, os alunos concluíram que não era possível.

Depois disso, reuniu todos os alunos para discutir os resultados e entregou um retângulo para cada um, para que dividissem em duas metades. Apresentou alguns não-exemplos (figuras que foram divididas de forma não igual e que, portanto, não representavam metades). Um dos alunos, dividiu de forma não canônica, unindo dois vértices opostos de uma mesma diagonal. O professor questionou se de fato o retângulo ficou dividido em duas partes iguais, e, depois de abrir a discussão, recortou e mostrou que as duas partes se sobrepunham e que, portanto, tratavase de duas metades. Fez um procedimento semelhante com triângulos e quadrados.

Finalizada a aula, os professores retornaram para a sala de aula, e, de posse de todo o material presente na aula, discutiram que aspectos da Mastery Approach foram mobilizados. Dando sequência ao encontro, a professora apresentou alguns problemas que mobilizavam 
aspectos da abordagem e sugeriu que os professores organizassem os encontros em suas escolas, finalizando com a avaliação do encontro e dos trabalhos até ali desenvolvidos."

Comentários: Um aspecto que não aparece claramente nos materiais de formação, mas que é central no trabalho de sala de aula e que foi aqui relatado é o uso das Stem Sentences. Trata-se de um extenso conjunto de sentenças que são utilizadas para auxiliar as crianças com a estrutura matemática. A sentença utilizada pelo professor assim aparece em materiais de formação:

Quadro 2: Exemplo de Stem Sentence

O inteiro está dividido em partes iguais. Cada parte é uma metade.

Fonte: materiais de formação, arquivo do autor (tradução do autor)

Espera-se que os alunos, preencham a lacuna em voz alta. O professor se vale da sequência: "Eu digo...", "Você diz...", "Nós dizemos...".

Outro exemplo de Stem Sentence, agora para multiplicação e apoiado na representação matricial:

Quadro 3: Exemplo de Stem Sentence

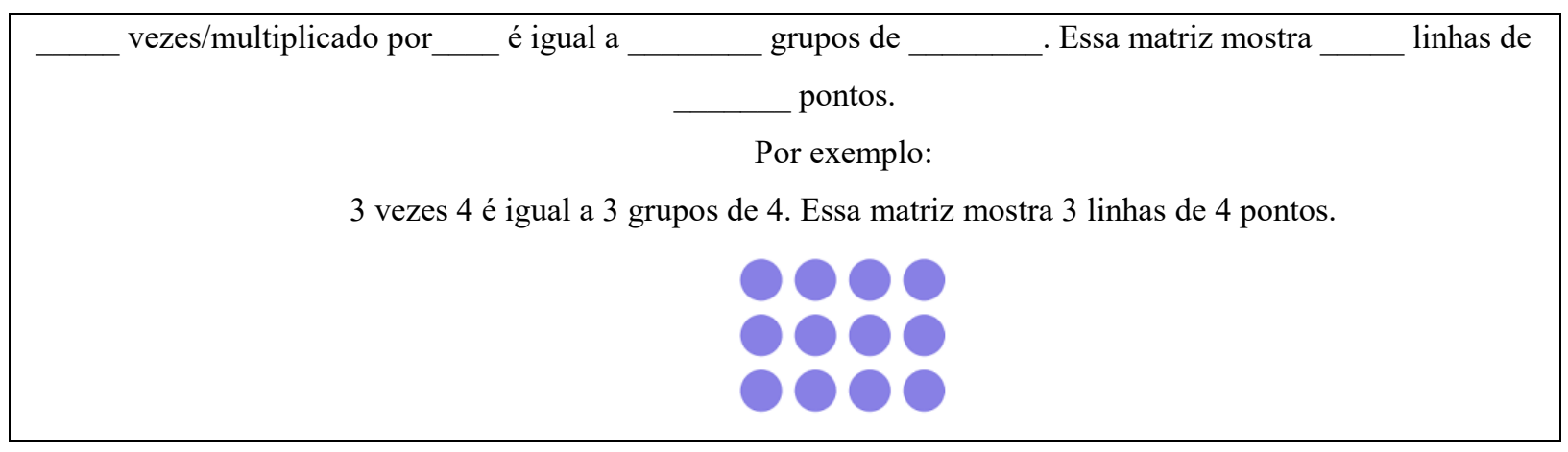

Fonte: Materiais de formação, arquivo do autor (tradução do autor)

Sobre a questão da fluência, não se encontra indícios claros dentro da Educação Matemática brasileira, bem como sobre o uso das Stem Sentences. Quanto a fluência, percebese que, embora prescinda da memorização de fatos básicos, é ancorada em representações, o que pode trazer benefícios aos estudantes. Já no caso das Stem Sentences, de acordo com as observações realizadas, ficaram restritas à repetição da sentença, com a crença de que tal repetição possa assegurar uma correção da linguagem a alunos e professores (lembrando que raramente passam por um curso de Matemática aos moldes brasileiros).

O desenvolvimento do pensamento matemático é mobilizado a todo momento, tanto nas observações realizadas como no estudo dos materiais. Tal trabalho tem adesão dos professores, pois o GCSE segue os mesmos pressupostos. O GCSE, ao contrário do ENEM - Exame 
Nacional do Ensino Médio é constituído por itens discursivos o que fornece mais liberdade ao elaborador de explorar diferentes conexões e ao corretor de valorizar o raciocínio do aluno. Isso é percebido pelos professores, que, conforme notamos, sofrem uma grande pressão por resultados e procuram então, incorporar os pressupostos do GCSE em suas salas de aula.

Compreende-se que o mesmo ocorre no Brasil, tanto para a ampliação do IDEB - Índice de Desenvolvimento da Educação Básica, que tem em sua composição a nota da PROVA BRASIL, como, mais tarde, em relação ao ENEM. No entanto, tendo em vista a população estudantil brasileira, tais avaliações se pautam pela TRI - Teoria de Resposta ao Item que limita a matriz de descritores, que implica na utilização de itens de múltipla escolha e impõe a verificação de apenas um descritor por item, o que impede que um item possa abordar a conexão entre mais de um descritor. Tais fatos devem ampliar ainda mais as críticas as avaliações de larga escala, que, aqui no Brasil, acabam sendo indutoras do currículo de sala de aula (Bertagna, Polato \& Mello, 2018) e, mais recentemente, acabaram se tornando indutores da própria Base Nacional Comum Curricular (Rolkouski, 2018).

No entanto, ainda com adesão dos professores, pode-se notar que não são poucas as vezes que os professores se queixam de que o trabalho de acordo com o Mastery Aproach consome mais tempo que o disponível para cumprir todo o currículo. De maneira similar, o professor Cristiano Alberto Muniz, assim relata suas percepções no programa Gestar, em entrevista concedida ao pesquisador Jeser Caleb Candray Menjívar:

Não adianta uma proposta da natureza do GESTAR II sem as mudanças de estrutura que permitam ao professor experimentar outras lógicas curriculares. Mas isso não houve, não houve... Ficou a formação pela formação. E o que aconteceu? O professor fazia aquelas experimentações como tarefa da formação e não como uma transformação das suas práticas. Ao fim da formação ele pergunta ao diretor - ou ao coordenador ou secretário da educação - : O que eu tenho que fazer? E ouve: Existe uma matriz do SAEB, você tem que a seguir porque em novembro os alunos vão ser avaliados. Então ele deixa a formação de lado, mesmo se acredita nela, mas o sistema não permite que ele faça essa ruptura. Eu acho que a política pública de formação, assim isolada, ela não transforma, ela deve estar associada com políticas de apoio ao professor, de repensar o currículo, de avaliação do sistema ... todas elas acopladas. (Menjívar, 2018. p. 123)

Na ocasião da organização do PNAIC, observou-se um movimento diferenciado nesse sentido que foi negligenciado no processo de construção da BNCC e, posteriormente na implantação do programa Mais Alfabetização. Na emergência da criação do PNAIC, especialistas foram ouvidos e juntos construíram o documento Elementos Conceituais e Metodológicos para a Definição dos Direitos de Aprendizagem e Desenvolvimento do Ciclo de Alfabetização do Ensino Fundamental (Brasil, 2012b). Na mesma direção, estabeleceu-se um diálogo entre participantes do PNAIC e o INEP - Instituto Nacional de Estudos e Pesquisas 
Educacionais Anísio Teixeira para o estabelecimento de uma avaliação de larga escala, a ANA - Avaliação Nacional de Alfabetização. Com as mudanças políticas ocorridas a partir do ano de 2016, todo esse processo de discussão de avaliação e alteração curricular que ocorria no âmbito do PNAIC foi descontinuado ${ }^{14}$.

\section{Considerações Finais}

Este artigo teve como objetivo descrever e analisar uma política pública de formação continuada da Inglaterra. A descrição realizada levou em conta os campos administrativos, operacionais e conceptuais. A análise foi empreendida a partir do estabelecimento de diálogos com políticas públicas brasileiras, sem desconsiderar o contexto em que ações dessa natureza são realizadas.

Foram observadas aproximações na operacionalização - a utilização do formato de rede, com vistas a atingir uma larga escala de forma presencial - e aproximações na concepção de Educação Matemática - o foco no desenvolvimento do pensamento matemático. Por outro lado, foram observados distanciamentos, ora decorrentes das diferenças de contexto político e administrativo, como, por exemplo, na forma de participação de sociedades civis em políticas de larga escala, como na concepção de formação continuada de professores, dentre elas a ausência de bibliografia e de elementos culturais nos materiais de formação ingleses, ao contrário do que ocorre no Brasil.

Além desses elementos, destacamos que se observa na política inglesa um movimento de aproximação às concepções chinesas de Educação Matemática, tendo em vista os altos índices de sucesso alcançados no PISA. Tais movimentos de aproximação nos alertam a um processo homogeneizador de práticas, de currículos e de racionalidades.

Segundo o INEP, o "objetivo do Pisa é produzir indicadores que contribuam para a discussão da qualidade da educação nos países participantes, de modo a subsidiar políticas de melhoria do ensino básico." (Brasil, 2017). Poderíamos perguntar: "políticas de melhoria do ensino básico, ou políticas de equivalência?”. Discutir a qualidade a partir de resultados em testes internacionais sem a devida compreensão dos contextos apaga racionalidades alternativas, apaga marcas culturais.

Não obstante as situações de importação de abordagens pedagógicas, currículos e avaliações, das quais a política inglesa e a BNCC são exemplos, no mundo globalizado e

\footnotetext{
${ }^{14}$ Sobre esse percurso, o leitor poderá consultar Rolkouski (2018).
} 
homogeneizante ainda há espaço para alternativas, como o currículo regionalizado do Estado Plurinacional da Bolivia (Aguilera Urquiza \& Gonçalves, 2017), que nos incita a refletir sobre processos de construção curricular centrados em aspectos antropológicos, tomando o conhecimento histórico e socialmente posicionado a partir da diversidade cultural e a Prova Campinas (Miguel, Moura \& Ferreira, 2016) para um exemplo de outras alternativas de avaliação de larga escala.

Ao estabelecermos os mesmos pontos de chegada, as alternativas postas serão sempre a daqueles que se impuseram como melhores, que, a médio prazo, serão as únicas existentes, e, ao fim... uma única. Olhar para o outro não deveria significar imitar o outro, mas sim deveria significar um estímulo a repensarmos a si mesmos, a refletirmos sobre ações, e uma inspiração a nos (re) criarmos.

\section{Agradecimentos}

Agradeço ao CNPq pela bolsa de Pós-Doutorado concedida no âmbito do Programa Nacional de Pós-Doutorado no Exterior.

\section{Referências}

AGUILERA URQUIZA, A. H. \& GONCALVES, H. J. L. (2017). Currículos Intra/Intercultural Na Bolívia: a Matemática e a perspectiva pós-colonial. Cadernos de Pesquisa, v. 24, 41 58.

ASKEW, M., BISHOP, S., CHRISTIE, C., EATON, S., GRIFFIN, P. \& MORGAN, D. (2015). Teaching for Mastery: questions, tasks and activities to support assessment (Year 4). Oxford: Oxford Press.

BERTAGNA, R. H., POLATO, A. \& MELLO, L. R. (2018). As avaliações em larga escala e o currículo no Estado de São Paulo: a realidade escolar desvelando as lógicas subjacentes. Currículo sem Fronteiras, v. 18(1), 52-70.

BRASIL (2007). Ministério da Educação. Programa Gestão da Aprendizagem Escolar GESTAR I: disposições gerais. Brasília, DF: MEC.

BRASIL (2012a). Ministério da Educação. Pró-letramento: guia geral. Brasília, DF: MEC.

BRASIL (2012b). Ministério da Educação. Elementos conceituais e metodológicos para definição dos direitos de aprendizagem e desenvolvimento do ciclo de alfabetização $\left(1^{\circ}, 2^{\circ}\right.$ e $3^{\circ}$ anos) do ensino fundamental. Brasília, DF: MEC. 
BRASIL (2013). Ministério da Educação. Programa Gestão da Aprendizagem Escolar GESTAR II: disposições gerais. Brasília, DF: MEC.

BRASIL (2014). Ministério da Educação. Pacto Nacional pela Alfabetização na Idade Certa: caderno de apresentação. Brasília, DF: MEC.

BRASIL (s/d). Instituto Nacional de Estudos e Pesquisa Anísio Teixeira. PISA. Recuperado de http://portal.inep.gov.br/pisa.

BRITIS, K. G. (2017). A trajetória de uma educadora matemática paulista como curriculista e formadora de professores de matemática (Dissertação de mestrado Profissional em Ensino de Ciências e Matemática). Universidade Cruzeiro do Sul, São Paulo.

CINTRA, C. C. (2017). Um estudo do ensino de frações para $7^{\circ}$ ano: desde um diagnóstico à aprendizagem mediada por Modelo de Barra (Dissertação de Mestrado Profissional em Matemática). Universidade Federal de São Carlos, São Paulo.

COLOMBO, J., FLORES, C. \& MORETTI, M. (2008). Registros de representação semiótica nas pesquisas brasileiras em Educação Matemática: pontuando tendências. Zetetiké, v. $16(29), 41-72$.

DEPARTMENT FOR EDUCATION - UK (2016). South Asian method of teaching maths to be rolled out in schools. Recuperado de https://www.gov.uk/government/news/south-asianmethod-of-teaching-maths-to-be-rolled-out-in-schools.

FERRETI, C. J. \& SILVA, M. R. (2017). Reforma do Ensino Médio no contexto da Medida Provisória $\mathrm{n}^{\mathrm{o}}$ 746/2016: Estado, currículo e disputas por hegemonia. Educação $e$ Sociedade, v. 38(139), 385-404.

GÓIS, R. C. (2014). O efeito do material concreto e do modelo de barras no processo de aprendizagem significativa do conteúdo curricular de frações pelos alunos de $7^{\circ}$ ano do ensino fundamental (Dissertação de mestrado em Ensino de Ciências Exatas). Universidade Federal de São Carlos, São Paulo.

GONÇALVES, S. R. V. G. (2017). Interesses mercadológicos e o "novo" ensino médio. Revista Retratos da Escola, v. 11 (20), 131-145.

IMBERNÓN, F. (2009). Formação permanente do professorado: novas tendências. São Paulo: Cortez.

MENJÍVAR, J. C. C. (2018). CFD E GESTAR II: compreensões sobre a formação continuada de professores que ensinam matemática a partir de um estudo comparado (Dissertação de mestrado em Educação em Ciências e em Matemática). Universidade Federal do Paraná, Paraná.

MIGUEL, A., MOURA, A. R. L., SILVA, L. L. M. \& FERREIRA, N. S. A. (2016). Prova Campinas 2010: entre usos alegóricos e normativos de linguagem. Zetetiké, v. 23, 179-212.

NCETM (2017). Five Big Ideas in Teaching for Mastery. Recuperado de http://www.ncetm.org.uk/resources/50042. 
NESI, E. R. \& ZANELLA, J. L. (2016). PDE/PR: os limites e as possibilidades de uma formação teórico metodológica do professor de matemática em um programa de formação continuada. Educação Matemática e Pesquisa, v.18(2), 975-987.

QUEIROZ, J. M. S. (2014). Resolução de Problemas de Pré-álgebra e Álgebra para Fundamental II do Ensino Básico com auxílio do Modelo de Barras (Dissertação de mestrado em Ciências Exatas e da Terra). Universidade Federal de São Carlos, São Paulo.

PARCIANELLO, J. (2015). Formação continuada de professores de matemática no estado do Paraná a partir do Projeto Folhas (Dissertação de mestrado em Educação). Universidade Estadual do Oeste do Paraná, Paraná.

PONTE, J. P., BROCARDO, J. \& OLIVEIRA, H. (2004). Investigações Matemáticas na sala de aula. São Paulo: Editora Autêntica.

ROLKOUSKI, E. (2018). Dos Direitos de Aprendizagem e do Pacto Nacional pela Alfabetização na Idade Certa à Base Nacional Comum Curricular: o caso da alfabetização matemática. Horizontes, v. 31(1), 119-131.

SANTOS, E. A. M. (2017). O PNAIC no município de Dois Vizinhos: curiosidades sobre sua implantação. Jornal de Políticas Educacionais, v. 11(6), 1-21.

TEIXEIRA, E. C. (2002). O Papel das Políticas Públicas no Desenvolvimento Local e na Transformação da Realidade. Revista AATR, v. 1(6), 1-11.

Submetido em: 04/09/2018

Aceito em: 11/06/2019 